\title{
O SER E O TRABALHO: UM ESTUDO DE AVALIAÇÃO DE FATORES INDICATIVOS DE SATISFAÇÃO
}

\author{
Being and Working: a factor evaluation study satisfaction indicatives ${ }^{1}$
}

\author{
LIMA, Samuel Rodrigues ${ }^{2}$, BEZERRA, Sefisa Quixadá3, LEONIDO, Levi ${ }^{4}, \&$ MORGADO, Elsa ${ }^{5}$
}

\begin{abstract}
Resumo
A satisfação com o trabalho possui importante relevância para o bem-estar dos colaboradores e consequentemente proporciona melhor desempenho em suas atividades. Alguns autores consideram que para se ter noção adequada de como mensurá-la deve-se analisar a relação do colaborador com alguns fatores, dentre os quais sempre são estudados pela literatura da área e por isso escolhidos para compor esse trabalho: a natureza e condições do trabalho, salário, sistema de promoções de cargo, equipe de trabalho e o superior imediato. Neste sentido, o presente estudo buscou avaliar o nível em que os referidos fatores indicativos de satisfação estão impactando no trabalho de colaboradores de um empreendimento no setor de panificação em Sobral-CE. Para tanto, realizou-se uma pesquisa exploratória descritiva referenciada com levantamento de dados em campo, tendo como método o estudo de caso. Os principais autores pesquisados foram Bergamini (2000), Chiavenato (2003), Tamayo (1998), Sarathy e Barbosa (1981) e Martinez e Paraguay (2003). Os resultados demonstraram que quanto às dimensões natureza do trabalho, superior imediato e equipe de trabalho, no local pesquisado, a avaliação foi muito positiva, enquanto as dimensões ascensão de cargo e remuneração demonstraram uma satisfação na média quanto a esses quesitos e, havendo neles a possibilidade de avaliação por parte da empresa. Os resultados das dimensões são coerentes com os dados encontrados na avaliação geral com os indicadores de qualidade de vida.
\end{abstract}

\begin{abstract}
Job satisfaction is important for the well-being of employees and, consequently, provides better performance in their activities. Some authors consider that in order to have an adequate notion of how to measure it, the relationship of the employee with some factors must be analyzed, among which they are always studied by the literature of the area and therefore chosen to compose this work: the nature and conditions of the work. work, salary, job promotion system, work team and immediate superior. In this sense, the present study sought to assess the level at which the said factors indicating satisfaction are impacting the work of employees of a project in the bakery sector in Sobral-CE. To this end, an exploratory descriptive research referenced with data collection in the field was carried out, using the case study method. The main authors surveyed were Bergamini (2000), Chiavenato (2003), Tamayo (1998), Sarathy and Barbosa (1981) and Martinez and Paraguay (2003). The results showed that, regarding the nature of work, immediate superior and work team dimensions, in the researched location, the evaluation was very positive, while the dimensions of job and remuneration showed an average satisfaction regarding these questions and, possibility of evaluation by the company. The results of the dimensions are consistent with the data found in the general assessment with the quality of life indicators.
\end{abstract}

Palavras-chave: Satisfação no trabalho; Comportamento organizacional; Gestão de pessoas.

Key words: Job satisfaction; Organizational behavior; People management.

Data de submissão: dezembro de 2019 | Data de publicação: março de 2020.

\footnotetext{
${ }^{1}$ Comunicação parcialmente apresentada no INNODOCT/19, em Valência 6-8 de novembro de 2019.

2 SAMUEL RODRIGUES LIMA - Acadêmico do Curso de Administração da Universidade Estadual Vale do Acaraú - UVA, BRASIL. E-mail: samulima4@gmail.com

${ }^{3}$ SEFISA QUIXADÁ BEZERRA - Universidade Estadual Vale do Acaraú - UVA, BRASIL. Email.sefisaquixada@gmail.com

${ }^{4}$ LEVI LEONIDO - UTAD e Universidade Católica Portuguesa, PORTUGAL. Email: levileon@utad.pt

${ }^{5}$ ELSA MORGADO - UTAD e Universidade Católica Portuguesa, Centro de Estudos Filosóficos e Humanísticos, PORTUGAL. E-mail: elsagmorgado@gmail.com.
} 


\section{INTRODUÇÃO}

As pessoas passam a maior parte de seu tempo em organizações onde, de acordo com Chiavenato (2009), o ambiente de trabalho se caracteriza por condições físicas e materiais e também psicológicas e sociais. Essa afirmativa reforça a compreensão da importância de perceber o comportamento do ser humano nas organizações como um importante campo de estudo, em especial dando destaque ao aspeto emocional relacionado a satisfação do colaborador em suas responsabilidades de trabalho (Marqueze \& Castro Moreno, 2005).

Ultimamente, os estudos sobre o tema satisfação no trabalho têm se disseminado, o que tem fomentado o interesse de muito pesquisadores em avaliar e tentar encontrar respostas e meios que apresentem com mais clareza a sua importância, tendo em vista que o assunto refere-se a um fenômeno complexo e de difícil definição, pois é um estado pessoal, que varia de acordo com cada pessoa e situação ao longo do tempo e, que muitas organizações têm reconhecido que as pessoas são um importante fator para seu desenvolvimento (Azevedo \& Medeiros, 2010).

Locke (apud Martinez, Paraguay, \& Latorre, 2004, p. 56) menciona que a satisfação com o trabalho "pode afetar a saúde física e mental do trabalhador, interferindo em seu comportamento profissional e/ou social", impactando por meio de seus efeitos tanto a vida pessoal do ser como o seu desempenho profissional, o que pode ser positivo ou não para as organizações.

Spector (2003) referido por Bonfim, Stefano, e Andrade (2003, p. 6) afirma que “a satisfação no trabalho é uma variável que reflete como o individuo se sente em relação ao trabalho em seus diferentes aspetos e de forma geral, define em termos simples que satisfação no trabalho é o quanto as pessoas gostam do seu trabalho".

Para o homem conseguir viver e realizar-se, deve buscar contribuir com o meio se disponibilizando a trabalhar, assim monetizando seus esforços para pertencer à alguma organização como funcionário. Como recompensa, recebe salários e/ou outros meios de gratificações para suprir suas necessidades básicas, sociais e culturais. Deste modo a satisfação e a qualidade de vida no trabalho estão diretamente relacionadas com a organização e o indivíduo, considerando-se que este se permanecerá produtivo e satisfeito se suas expectativas forem atendidas (Karpinski \& Stefano, 2008). 
Nesse contexto questiona-se: comprova-se que se a organização der condições satisfatórias nas cinco dimensões (a natureza e condições do trabalho, salário, sistema de promoções de cargo, equipe de trabalho e o superior imediato) o colaborador responderá com resultados satisfatórios para a empresa e demonstrará isso em seu modo de se comportar na organização?

O objetivo geral desse estudo é avaliar o nível em que os referidos fatores indicativos de satisfação estão impactando no trabalho. São apresentados os fatores indicativos usados por Tamayo (1998), Sarathy e Barbosa (1981) como referência o estudo em campo, que são: satisfação com o salário, colegas de trabalho, superior imediato, ascensão de cargo e trabalho em si, e ao modelo de qualidade de vida proposto por Walton (1974 apud Alves, 2010, p. 79), se estes influenciam na satisfação no trabalho dos colaboradores, tendo como estudo de caso uma empresa no segmento de panificação na cidade de Sobral - CE.

Especificamente buscou-se fazer um estudo a cerca do assunto satisfação no trabalho e seus indicativos, dimensões e conceitos na tentativa de entender como melhor trabalhar a temática. A partir desse estudo teórico sobre a satisfação no trabalho e suas vertentes foi feito o estudo em campo onde foram testadas as variáveis mais estudadas dos instrumentos encontrados. Partiu-se da perspetiva que os colaboradores se sentiam mais satisfeitos com a sua relação com o seu trabalho, mais com o que realizavam e menos em relação às recompensas e condições de trabalho, independente do nível em que atuavam.

Inicia-se o estudo com abordagem acerca do comportamento humano nas organizações. Em seguida é explanado sobre a visão do homem sobre o trabalho, passando por conceituar a satisfação no trabalho. Posteriormente é apresentada a metodologia aplicada ao estudo e a análise dos dados da pesquisa realizada, bem como seus resultados. 


\section{REFERENCIAL TEÓRICO}

\subsection{O Comportamento Humano nas Organizações}

No campo da Teoria Geral da Administração - TGA, o comportamento humano nas organizações veio sendo estudado desde a escola de Administração Cientifica, fundada por Friederick W. Taylor, que procurou conhecer formas de maximizar a produção industrial no menor tempo, ignorando a essência humana e social, definindo que a única fonte motivacional do trabalhador centrava-se na concessão do salário, criando a definição de "homo economicus" (Chiavenato, 2003).

Visando corrigir a forte tendência a desumanização no trabalho defendida pelo pensamento taylorista, o psicólogo Elton Mayo desenvolveu a Teoria das Relações Humanas, definindo o "homem social" ao reconhecer que os trabalhadores possuem sentimentos, temores, desejos e singularidades sociais que são motivadas por certas necessidades, e só alcançam sua satisfação através dos grupos com os quais interagem (Carvalho, 2002). Após os estudos de Taylor e Mayo foram desenvolvidas diversas teorias que reforçaram a ênfase dada às tarefas e pessoas, e indo além, analisando os impactos da estrutura, do ambiente e da tecnologia para as organizações. Com esta evolução teórica nasceram novas concepções sobre o homem, tais como Homem Organizacional e Administrativo durante a Teoria Neoclássica, Homem Organizacional nas Teorias da Burocracia e Estruturalista, Homem Administrativo na Teoria Comportamental, o Homem Funcional na Teoria de Sistema e o Homem Complexo na concepção da Teoria da Contingência (Chiavenato, 2003)

Deve-se citar que durante esta evolução, além dos estudos de Mayo, importantes pesquisadores deram ênfase ao comportamento humano no ambiente de trabalho, dentre eles Vergara (2010) destacou as contribuições de Abrahan Maslow com a Teoria das Necessidades, Frederick Herzberg e sua Teoria dos Dois Fatores, McClelland defendendo a Teoria das Necessidades Secundárias, a Teoria da Expectativa de Victor Vroom e a Teoria da Equidade de J. Stacy Adams.

Nesta breve introdução percebe-se que o papel humano foi questionado e adaptado a cada época e cenário. Isso evidencia a relevância do comportamento humano para as organizações. Não se deve esquecer que uma empresa só passa a existir quando há uma união de pessoas capazes de compartilhar seus conhecimentos e que estejam dispostas a cooperarem a fim de alcançarem um objetivo comum. 
Como visto nas teorias comportamentais, o homem necessita que algumas condições ocorram no trabalho para que possa sentir-se impulsionado a entregar resultados. Deve-se, portanto, cuidar em haver reciprocidade nas relações indivíduo/trabalho levando sempre em consideração que as pessoas buscam satisfações pessoais (salários, lazer, conforto e etc.) e as organizações do mesmo modo procuram atender suas necessidades (capital, equipamentos, potencial humano e etc.) (Chiavenato, 2002). Neste sentido verifica-se uma dependência entre o colaborador e a empresa quanto suas necessidades, deste modo havendo a necessidade de equilíbrio nessa relação para que os lados fiquem satisfeitos.

\subsection{O Trabalho dignifica o homem. O Trabalho significa para o homem}

A origem da palavra trabalho vem de uma transformação do vocabulário latino tripalium, que designava um instrumento de tortura formado por três paus cruzados, assim, conotando uma ideia de castigo e sofrimento. Porém, com o passar dos séculos esse conceito foi sendo suavizado (Oliveira, 2010).

O trabalho abrange grande parte da vida das pessoas e pode ser visto como fonte de significado pessoal, reconhecimento, gratificação econômica, meios de obter autorrealização e autodesenvolvimento (Pereira, 2006). Martinez (2003) nos diz que o trabalho é uma das melhores formas de o homem expressar sua singularidade, algo que o completa e dá sentido a vida, por esse motivo, é visto como uma das fontes da felicidade humana, onde a felicidade no trabalho é alcançada através da satisfação plena e necessidades biopsicossociais, da sensação de bem-estar e do sentido de utilidade no exercício de suas responsabilidades no trabalho.

O modo como se conhece o trabalho nas organizações atualmente se inicia com a Revolução Industrial. Segundo Motta (2001), foi ela que lançou a especialização dos papéis sociais: onde o trabalho separa-se da casa e da família e adquire uma esfera social particular e mais autônoma, sendo exercido em ambientes próprios e com novas relações de produção. Com o mundo fabril, o trabalho, já diferenciado de outras funções sociais, tornou-se o centro da vida humana e das preocupações sociais. 
Como visto anteriormente sobre o comportamento humano nas organizações, ocorreram evoluções na forma de ver o homem nas empresas. Da forma mecânica e desumana o olhar foi sendo moldado até 1970 quando, quando de acordo com Chiavenato (2004), surgiu o conceito de administração de Recursos Humanos (ARH), mesmo que ainda considerando as pessoas como agentes passivos no processo produtivo em que realizam suas atividades conforme o planejamento e controle das organizações. Atualmente já se discute com maior compreensão a necessidade de equilíbrio nas relações homem - trabalho, onde o ser já não é visto como objeto, mas como instrumento estratégico à empresa, constituindo seu principal ativo (Chiavenato, 2004).

De acordo com Frankl (2003), o Homem só se torna homem e só é completamente ele mesmo quando fica absorvido pela dedicação a uma tarefa, quando se esquece a si mesmo no serviço a uma causa ou no amor a uma pessoa. Nesse sentido defende-se que o homem necessita de motivos pelos quais possa encontrar significado no que realiza. Para isso, é preciso que o ambiente de trabalho proporcione algumas condições essenciais. Deste modo o funcionário identificará incentivos que o levarão a produzir os resultados esperados, e em alguns casos indo além. Esse fato trás à reflexão que a satisfação do colaborador é subjetiva e que no ambiente corporativo se devem considerar fatores que compõem sua condição biopsicossocial, quais poderão influenciar em seu comportamento e interferir em sua saúde física e mental.

Em suas pesquisas sobre a Psicodinâmica do trabalho, Dejours e Abdoucheli (1994) extraíram aquilo que era potencialmente desestabilizador para a saúde mental dos trabalhadores. Identificaram que todas as pressões aparecem como decorrentes da organização do trabalho, esta que foi conceituada pelo contraste com as condições do trabalho, quais devesse entender como sendo as pressões físicas, mecânicas, químicas e biológicas do posto de trabalho. As pressões ligadas às condições de trabalho têm por alvo principal o corpo dos trabalhadores, onde elas podem ocasionar desgaste, envelhecimento e doenças somáticas. Importante ressaltar que, ainda segundo Dejours e Abdoucheli (1994), se por um lado as condições de trabalho têm por alvo principalmente o corpo dos colaboradores, a organização do trabalho, por outro lado, atua a nível do funcionamento psíquico. Sendo assim, a divisão das tarefas e o modo operacional estimulam o sentido e o interesse do trabalho para o sujeito, enquanto a divisão de homens solicita, sobretudo, as relações entre pessoas e mobiliza os investimentos afetivos como o amor e o ódio, a amizade e a solidariedade. 
Em vista do que se argumentou, reforça-se que as pessoas compõem a principal estrutura de uma organização. As empresas terão êxito a partir da forma que as pessoas se comportam em seu ambiente de trabalho. Portanto, é fundamental um espaço que disponha de condições satisfatórias para o bom desempenho dos envolvidos (Mendes, 2014).

\subsection{Satisfação no trabalho}

De acordo com Martinez e Paraguay (2003, p. 61):

A satisfação no trabalho é um fenômeno amplamente estudado, e esse interesse decorre devido à influência que ela pode exercer sobre o trabalhador, afetando sua saúde física e mental, atitudes, comportamento profissional, social, tanto com repercussões para a vida pessoal e familiar do indivíduo como para as organizações.

Segundo Klijn (1998), os estudos sobre o tema iniciaram-se na década de 30 e desde então geram interesse em profissionais e pesquisadores de diversas áreas. Ressaltando a relevância atual do tema, Moretti (2010 referido por Martins \& Santos, 2006, p.1) citam que a "satisfação no trabalho é estudada como uma das mais importantes variáveis da área de comportamento organizacional”.

Conforme Cura (1994 referido por Martinez \& Paraguay, 2003), não existem conceitos, teorias ou modelos teóricos de satisfação no trabalho, o que têm provocado dificuldades e até mesmo falhas metodológicas em estudos sobre o tema. De acordo com Moretti (2010) o que existem são várias percepções diferentes, que incorporam diferentes dimensões. Para contextualizar esta pesquisa adotamos o conceito de Pereira (2003, p.9), que delibera que "a satisfação no trabalho é o resultado dos sentimentos positivos e negativos que uma pessoa apresenta em relação ao seu trabalho, ou seja, é uma resposta emocional determinada pela interação das tarefas desempenhadas, das condições físicas e sociais do local de trabalho". Portanto, expressa uma relação entre o que o colaborador espera de seu trabalho e o que ele acredita que está obtendo, funcionando como um "contrato psicológico" onde estão definidas as expectativas sobre o que será realizado no trabalho, em benefício da empresa, e o que será recebido em troca, seja por meio de incentivos simbólicos, materiais, intelectuais, sociais ou mistos.

Quando há o sentimento de que a relação do contrato de trabalho está gerando equilíbrio entre as contribuições e compensações no ambiente de trabalho, haverá uma tendência de satisfação positiva para o funcionário. Em caso oposto, o colaborador 
demonstra insatisfação em alguma das dimensões do trabalho, passa a se reservar e atacar, contrariando a empresa das formas que puder desde que não seja diretamente prejudicado.

A satisfação no trabalho é uma variável multifatorial, ponderando que os fatores estudados regularmente são com a natureza do trabalho, salário, sistema de promoções, colegas e com os gerentes. Isso quer dizer que a atitude do colaborador não acontece diante do trabalho como um todo, mas diante o trabalho e diversos aspectos a ele relacionados (Tamayo, 1998).

Os fatores que se enquadram como psicossociais, foram identificados em 1984 pela Organização Internacional do Trabalho como sendo: interação entre e no meio ambiente de trabalho, conteúdo do trabalho, condições organizacionais e habilidades do trabalhador, necessidades, cultura, causas extra-trabalho pessoais e que podem, por meio de percepções e experiência, influenciar a saúde, o desempenho no trabalho e a satisfação no trabalho.

Para evitar conflitos de interpretação é necessário diferenciar satisfação de motivação e identificar o que a satisfação representa para a qualidade de vida do colaborador. Greenberg (1999, p.50) “os cientistas definiram a motivação como o processo que desperta, dirige e mantem um comportamento que se orienta para um determinado objetivo". Para a autora isso envolve uma energia por trás das ações, a escolha por uma orientação e persistência em exercer um esforço até que se alcance o objetivo. Denota-se, portanto, que a energia a qual Bergamini (2010) relata pode advir do nível de satisfação do colaborador, e que esta motivação poderá gerar níveis de satisfação no trabalho que impactarão de diversas formas no comportamento do servidor e em seus resultados para a organização em que atua.

A satisfação no trabalho pode repercutir de diversos modos em uma organização.

Uma das formas pode ser expressa através do desempenho do empregado (Azevedo \& Medeiros, 2012). As autoras citam Spector (2003, p. 241) quando este apresenta duas variáveis da conexão da satisfação no trabalho com o desempenho. A primeira aborda a ideia de que "a satisfação deve resultar do desempenho", ou seja, quando o trabalhador estiver satisfeito poderá cumprir melhor e com mais prazer sua ocupação, enquanto a segunda se opõe indicando que "o desempenho deve resultar da 
satisfação". Pereira (2004, p, 285) indica que a "produtividade e satisfação não se relacionam de uma forma linear".

Um outro assunto muito atrelado a satisfação e motivação que também congrega para o bom desempenho do colaborador é qualidade de vida extensiva ao trabalho.

Segundo Nishimura, Spers e Giuliani (2008 apud Passarinho, Passarinho, Silva, Cardoso, Junior, \& Ribeiro Neto, 2016, p. 1) “A QVT é uma abordagem baseada na filosofia humanista - cujo sentido prega a valorização do trabalhador como ser humano e busca o equilíbrio entre o indivíduo e a empresa, gerando benefícios a ambos”. A implantação da QVT em uma corporação é uma ferramenta indispensável para perceber a importância dos funcionários. Os programas de QVT têm o objetivo de proporcionar espaços de trabalhos mais agradáveis, condições melhores nos aspectos: saúde, físico, emocional, social, além de buscar preparar as equipes, integrar os setores com seus superiores, entre outras vantagens que melhorem o nível de satisfação dos envolvidos com a instituição (Ribeiro \& Santana, 2015).

Alves (2010) relata que inúmeros instrumentos para avaliar a QVT têm sido criados e utilizados, sendo que parte deles apresentam a satisfação profissional como definição principal. O autor alerta que deve-se ter cuidado, pois a satisfação deve ser conceituada como apenas um dos indicadores existentes dentre os vários âmbitos de vida de um trabalhador. Caso apenas se tome este como base, pode não ser possível mensurar com precisão o colaborador. Dentre os instrumentos, Alves (2010), apresenta que o modelo de indicadores de QVT de Walton (1974) é um dos mais citados e usados em trabalhos acadêmico-científicos e, também em programas de implantação em empresas. Formado por oito critérios que afetam de modo significativo o trabalhador e podendo ser aplicado por meio de um questionário ou entrevista, o modelo consegue mensurar de modo simples o nível de satisfação com a QVT.

Além de melhorar o desempenho humano, deve-se mencionar que o atendimento das necessidades do colaborador, baseando-se nas dimensões: natureza do trabalho, salário, colegas de trabalho, superior imediato, ascensão de cargo, poderão gerar qualidade de vida, saúde, sensação de bem-estar e dar a ele melhores condições de conseguir interagir melhor com sua condição biopsicossocial a partir de mudanças de comportamento. 
Para a organização, são inúmeras as vantagens, pode-se prevenir a intenção de turnover, absenteísmo, reter talentos, melhora no clima organizacional, dentre outras. Compreende-se que conhecer mais sobre a satisfação no trabalho será válido para inteirar-se sobre os diversos fatores e suas interações que adequam a motivação do colaborador ao seu trabalho, almejando torná-lo mais realizado humana $\mathrm{e}$ profissionalmente.

\subsection{A Importância da satisfação no trabalho}

Primeiramente, faz-se a relação da satisfação no trabalho com a natureza do trabalho. Parte-se da perspectiva de que a empresa deve proporcionar um ambiente confortável para que os funcionários deixem fluir suas competências, pois segundo Aires (2003), há uma forte correlação entre o quanto os colaboradores estimam o contexto social de seu ambiente de trabalho e a satisfação que sentem no geral.

Considerando que a satisfação do profissional com o trabalho é um estado emocional advindo da interação com outros profissionais, suas peculiaridades pessoais, valores e expectativas com o ambiente e a organização do trabalho, concorda-se com Bergamini (2010) quando esta nos diz que as organizações que permitem o atendimento dos interesses e aspirações pessoais, também melhoram sua produtividade devido à forma individual com que consideram cada pessoa. O resultado do trabalho nos colaboradores compreende as reverberações dos fatores associados ao trabalho sobre a saúde e o sentimento de bem-estar da equipe (Rebouças, Legay, \& Abelha, 2007). Segundo Bergamini (1980, p.93),

Ao desenvolver uma atividade que não seja aquela que mais esteja de acordo consigo mesma, a pessoa passa a considerar a circunstância de trabalho como fonte de mal-estar e, na primeira oportunidade que se apresente, ela procurará livrar-se dela mudando de cargo ou até mesmo de emprego. Isso se constitui num mecanismo de defesa normal que visa sobretudo salvaguardar a própria individualidade e o bem-estar comumente perseguido por pessoas normais e produtivas.

Robbins (2010, p.65) afirma que "trabalhos interessantes que fornecem treinamento, variedade, independência e controle, satisfaz a maioria dos funcionários". Desta forma, quanto mais à empresa disponibiliza meios de crescimento e desenvolvimento, mais o servidor tende a ficar satisfeito com seu trabalho. 
Para o empregado estar satisfeito com o trabalho ele precisa também estar satisfeito com seu superior imediato, afinal por exercer função de liderança este deve saber orientá-lo e ao seu grupo. De acordo com Burns (referido por Bergamini, 2010) a liderança é a prática do poder, qualquer que seja ele, e esse é “ubíquo; permeia os relacionamentos humanos. Existe seja procurado ou não." Portanto, cabe ao líder a missão de levar ao funcionário incentivos que o faça sentir pertencer, além de saber conduzir diversas situações relacionadas ao comportamento deste, pois isso pode repercutir positiva ou negativamente no desempenho no seu e consequentemente na organização.

As relações interpessoais positivas no ambiente profissional proporcionam um trabalho saudável tanto para a equipe quanto para à organização em seu todo, proporcionando as pessoas, mais bem-estar em trabalhar. O relacionamento entre as pessoas no trabalho e o clima influenciam-se recíproca e circularmente, caracterizando um ambiente agradável e estimulante ou desagradável, podendo gerar satisfação ou insatisfação, essencial para manter a relação entre os indivíduos na organização (Azevedo $\&$ Medeiros, 2012).

Considerando agora os fatores extrínsecos de satisfação, inicia-se abordando a relação da satisfação no trabalho com a remuneração salarial e em seguida com políticas de ascensão. Segundo Davis e Newstrom (apud Carvalho, 2013) os empregados, além da busca por satisfazer suas necessidades, também aspiram que o modo de recompensas seja correto. Assim sendo, tendem a verificar suas contribuições pertinentes ao trabalho com as remunerações que recebem e também comparam essa relação com as de outras pessoas da própria empresa, da comunidade e/ou da sociedade.

Azevedo e Medeiros, 2012, p.82) aponta que "partindo do contrato de trabalho, o trabalhador despende energia para produzir em força de uma remuneração pelo trabalho, com a qual reproduz sua energia: o salário”. Com essa concepção, percebe-se que salário tem um papel essencial para o trabalhador permitindo que este possa adquirir bens, satisfazendo assim suas necessidades básicas. Todavia, esse benefício não pode ser suspenso, pois isso pode causar atitudes de insatisfação. Quanto à remuneração, pode-se ainda mencionar que ela atrai os profissionais, mas não os fixa em uma empresa.

Deve-se considerar que cada indivíduo, ao longo de sua vida de trabalho, tenta colocar-se nas áreas que contemplem atividades para as quais se sinta mais capaz e, quais 
estejam mais de acordo com aquilo que lhe possa trazer satisfação pessoal em termos de autorrealização. Desse modo, as visões das políticas de promoção justas devem prevalecer para o funcionário. Caso perceba que há certa desvalorização de seu potencial, em detrimento de outrem, em especial de contratação de pessoal externo, poderá gerar consequências negativas quanto ao seu desempenho como descompromisso com sua função. Deve-se observar que o ajustamento pode ser considerado como normal, quando as necessidades humanas são satisfeitas dentro das exigências impostas pela própria natureza humana. $\mathrm{O}$ descompasso entre os objetivos individuais e organizacionais leva ao conflito e, consequentemente, ao estresse, que quando enfrentado adequadamente, representa um terreno fértil ao desajustamento individual (Bergamini, 2010).

Segundo Oliveira (2010, p. 23), o “estresse é o conjunto de reações adaptativas do organismo a quaisquer perturbações de ordem física ou psíquica capazes de retirá-lo de seu estado de equilíbrio.” É a forma do corpo se defender contra agressões advindas do ambiente externo, buscando um reajustamento. O estresse fisiológico pode causar uma adequação "normal” do organismo à nova situação, podendo também representar uma resposta patológica, que gera desordem e leva a distúrbios transitórios ou doenças mais críticas. Bergamini (2008) apresenta em um capítulo de sua obra sobre psicopatologias do comportamento organizacional, alguns dos mais importantes e frequentes quadros clínicos que podem comprometer o ajustamento do colaborador, sendo eles: neuroses histérica, fóbica e obsessivo-compulsiva; transtornos de humor, episódios depressivos, episódios maníacos, psicoses, esquizofrenia, paranoia e narcisismo.

\section{METODOLOGIA}

A realização desta pesquisa teve como propósito investigar o nível da satisfação no trabalho de acordo com os fatores indicativos usados por Tamayo (1998) e Sarathy e Barbosa (1981) que são: satisfação com o salário, colegas de trabalho, superior imediato, ascensão de cargo e trabalho em si, e ao modelo de qualidade de vida proposto por Walton (1974).

A pesquisa aplicada de natureza exploratória descritiva. Por meio da análise dos resultados baseada na percepção do público pesquisado, buscou-se as dimensões com maiores e menores níveis de satisfação para entendimento e reconhecimento na prática 
sobre o assunto e também repassar aos gestores, que aceitaram o estudo na sua empresa, as informações resultantes do estudo para que que possam contribuir para melhorias em alguma(s) dimensão(ões).

Por buscar conhecer como está o nível de satisfação no trabalho de uma organização específica pode-se caracterizar a presente pesquisa como qualitativa, tendo como método o estudo de caso (Yin, 2001).

Também possui caráter quantitativo, tendo utilizado técnicas quantitativas para sua análise, os dados foram trabalhados e analisados através do software estatístico SPSS versão 22.0 e Excel 2010. A interpretação dos dados por meio destes softwares permite obter conhecimentos sobre o perfil dos profissionais participantes, nível de satisfação em relação às dimensões estudadas e avaliar o nível de QVT geral da organização.

O universo desta pesquisa correspondeu aos colaboradores das duas unidades de uma organização do setor de panificação em Sobral - CE, sendo composto por 59 colaboradores regidos pelo regime celetista com contrato formal de trabalho. A amostra correspondeu a 49 servidores que aceitaram responder o questionário entre os dias 18 e 19 de outubro de 2017, correspondendo a 83,05\% da população, tendo caráter do tipo não probabilístico por aceite. Pelo cálculo amostral, uma amostra de 42 elementos já seria suficiente para o proposto no estudo.

Aplicou-se para de coleta de dados um questionário dividido em 3 partes: (1) Pesquisa sociodemográfica; (2) pesquisa com afirmativas sobre fatores de satisfação no trabalho; e (3) pesquisa de avaliação dos indicadores de Qualidade de Vida no Trabalho.

Os dados principais foram obtidos através de questionário adaptado de um instrumento desenvolvido por Sarathy e Barbosa (1981) e apresentado como Escalas para Medir Satisfação com o Emprego - EMSE, adicionado de complementos para análise do perfil dos colaboradores e de um questionário adaptado pelo autor desse estudo baseado em seis dos oito indicadores de QVT propostos por Walton (1974, apud Alves, 2010, p. 79). No total o instrumento possui 78 questões (6 perguntas para análise do perfil do entrevistado, 66 questões com afirmativas da EMSE e 6 afirmativas sobre os indicadores de QVT).

Para avaliar as afirmativas sobre satisfação e QVT optou-se pelo uso da escala Likert tendo em vista que o modo mais comum de se aferir a satisfação no trabalho se dá 
por meio de escalas deste tipo, que buscam respostas sim, não e não concordo nem discordo, ou respostas a escalas de maior número de pontos (Martinez, 2002).

Foram utilizados os seguintes tipos de variáveis: variável ordinal, para resposta as afirmativas das escalas de satisfação com o emprego e com os indicadores de QVT, tipo Likert, sendo que nas afirmativas com as variáveis intrínsecas e nos indicadores de QVT variou de 1 a 5 (de discordo totalmente à concordo totalmente) e de 1 a 3 nas variáveis extrínsecas (tendo o mesmo parâmetro, porém sendo o número 2 a opção "nem concordo nem discordo"); variável nominal (sexo, estado civil e posição ocupada na instituição), variável numérica intervalar (faixa etária, faixa salarial mensal e tempo de trabalho na instituição). O instrumento foi aplicado pelo pesquisador.

\subsection{A Organização estudada}

O ano de fundação da empresa pesquisada data de 1999 e teve como seu idealizador o empreendedor Airton Frota, qual objetivou inicialmente atender o mercado de pães e bolos no bairro Campo dos Velhos e regiões vizinhas na cidade de Sobral - CE.

Desde 2010 é gerenciada pelo empresário Félix Ponte Frota, sendo este o representante do setor de panificação da região norte do estado, tem buscado juntamente com o corpo de colaboradores satisfazer os clientes proporcionando maior qualidade dos produtos oferecidos, excelência no atendimento, conforto nas instalações e apresentar constantes inovações.

As padarias possuem médio porte e seu nome é considerado um dos maiores e mais respeitados no segmento de panificação na cidade de Sobral. Atualmente possui duas lojas, sendo a matriz em um bairro tradicional da cidade e a outra no centro de Sobral. Foi escolhida por possuir quantidade de funcionários adequada para avaliação considerando-se as duas lojas e por ser apreciada como referência no setor de atuação.

Seu portfólio contempla pães, salgados e bolos de fabricação própria, além de mais opções como sucos, refrigerantes e doces. A estrutura física conta com ambiente para refeições, presta serviço de buffet para eventos, e espaço de conveniência para lanches rápidos e cafeteria.

O responsável pela organização autorizou a utilização do nome fantasia neste trabalho. 


\section{ANÁLISE DOS RESULTADOS}

Para este estudo aplicou-se um total de 49 questionários com funcionários das duas lojas da padaria Pão Mix. A partir dos dados fez-se necessária uma análise para a construção do estudo de caráter investigativo. Partindo desta condição, foi possível obter as informações que serão apresentadas adiante.

\subsection{Análise do perfil dos respondentes}

Foi possível observar certo equilíbrio quanto ao sexo dos entrevistados, sendo $51 \%$ representados por homens e $49 \%$ por mulheres. Quanto à faixa etária, a maioria dos colaboradores, $43 \%$, tem entre 21 e 29 anos e, a segunda maioria está entre 30 a 34 anos, representando 24,5\%. A maior parte dos respondentes é solteira, compreendendo $59 \%$ do total. Em relação à faixa salarial mensal, constatou-se que todos colaboradores recebem de 1 a 2 salários mínimos. Ao que tange a posição ocupada na empresa, 88\% está no nível operacional e $12 \%$ em nível tático especializado. Nenhum colaborador do nível estratégico respondeu a pesquisa. Quanto ao tempo de serviço na organização, constatouse que a maioria dos servidores, com 55\%, está na organização a menos de 1 ano. Em seguida, aparecem os funcionários que possuem de 2 a 4 anos e 11 meses no ambiente, equivalentes a $24,5 \%$.

\subsection{Nível de satisfação no trabalho de acordo com cada dimensão}

\section{a) Satisfação com a natureza do trabalho}

Conforme o Gráfico 1, constatou-se que os colaboradores das lojas Pão Mix estão parcialmente satisfeitos com o trabalho que realizam e o ambiente em que estão. Como parâmetro para esta afirmativa considera-se a média 4,22 obtida das 12 afirmativas de satisfação, e pela média de 2,66 das 5 de insatisfação, onde a última caracteriza que os colaboradores discordam em partes que determinadas condições ocorram, levando a deduzir que neste caso há equilíbrio nos polos satisfação e insatisfação. Dentre as afirmativas de satisfação destacaram-se as médias 4,71 e 4,69, respetivamente 7.s e 16.s, ambas relacionadas ao fator respeito, onde a primeira refere-se ao cargo e atividades realizadas para a organização e a segunda para as condições humanas e de identidade pessoal. Do polo de insatisfação houve destaque para a afirmativa 12.i - exaustivo, que 
se aproximou da média 4, indicando que grande parte dos respondentes concordam em partes com esta condição. Com as menores médias nas afirmativas de insatisfação, ficaram as afirmativas 13.i - trabalho frustrante e 4.i - enfadonho, ambas na casa 2, sugerindo coerência com as médias positivas relacionadas ao 1.s - encantamento, 3.s satisfação, 9.s - prazer, 6.s - uso de criatividade e 15.s - realização pessoal e 17.s profissional no ambiente de trabalho e com as atividades realizadas.

Há destaque positivo também na afirmativa trabalho 11.s - desafiador, o que denota repasse de autonomia para agir e se presume como algo positivo à medida que, os desafios apresentados pelas tarefas proporcionam desenvolvimento profissional, deste modo estimulando atitudes positivas dos colaboradores.

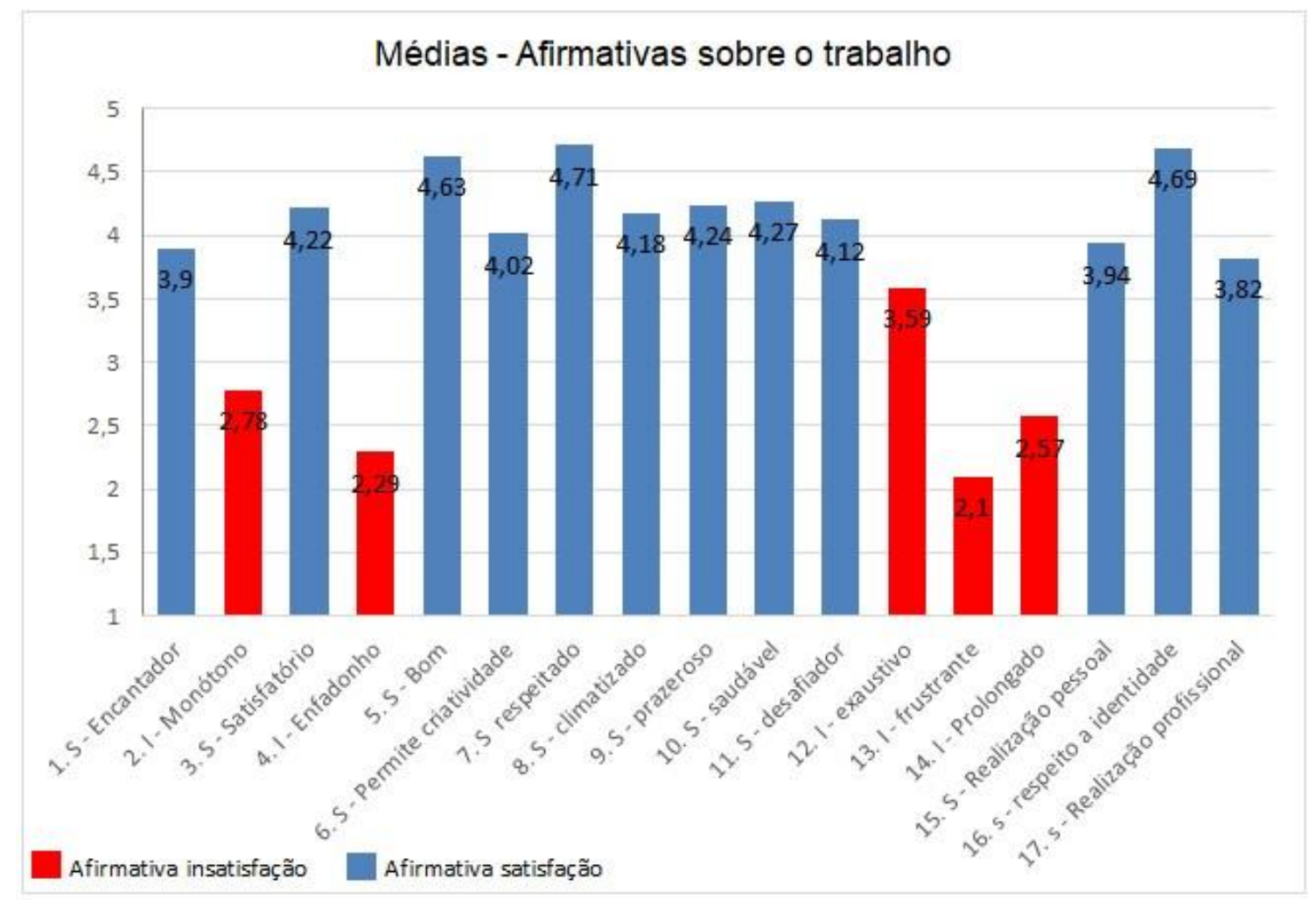

Gráfico 1 - Médias de Satisfação com a dimensão trabalho.

Fonte: Própria

\section{b) Satisfação com o superior imediato}

Pode-se observar no gráfico 2 que os servidores demonstram satisfação com seu superior tendo média total 4,39, a maior média de satisfação por dimensões da pesquisa, considerando-se as 13 afirmativas de satisfação. Com pontuação 1,52, os respondentes discordaram quase que totalmente das afirmativas que sugerem insatisfação. 
Nesta dimensão destacou-se a afirmativa 5.s que expressa que os superiores expressam respeito e buscam proporcionar bem-estar aos colaboradores, tendo média 4,73 e, coerente com a dimensão anterior, tem relação com respeito. Destaque também com médias acima de 4,5 às questões referentes à influência do líder na organização, 6.s, ao modo claro e definido qual repassam informações às suas equipes, 10.s, a forma como demonstram sua inteligência, 14.s, e o tratamento igualitário, sem favoritismos, 19.s.

Dentre as alternativas que indicariam insatisfação se sobressaíram às afirmativas que indagaram se o superior imediato é grosseiro, 3.i, preguiçoso, 17.i, e antipático, 11.i, obtendo médias abaixo de 1,5. Destaque maior para a primeira afirmativa que teve 1,1 como média, a mais baixa em toda a pesquisa, e que unida as outras duas representa discordância total com estas características.

Quanto a capacidade do líder e sua percepção sobre o que ocorre na organização, afirmativas 13.s e 7.s, os colaboradores demonstram satisfação, com média 4,45. Do mesmo modo houveram avaliações positivas com relação a preocupação destes em proporcionar segurança no trabalho, 18.s, e autonomia, 15.s, com médias 4,35. Destacou-se também que há reconhecimento quando há um trabalho bem feito, 4.s, com média 4,24 .

Estes dados indicam que há contentamento com a forma qual o líder age, concedendo liberdade, confiança ao colaborador para agir em algumas situações, e reconhecimento de trabalhos, gerando assim motivação, importante fator para o desenvolvimento do trabalhador e da organização.

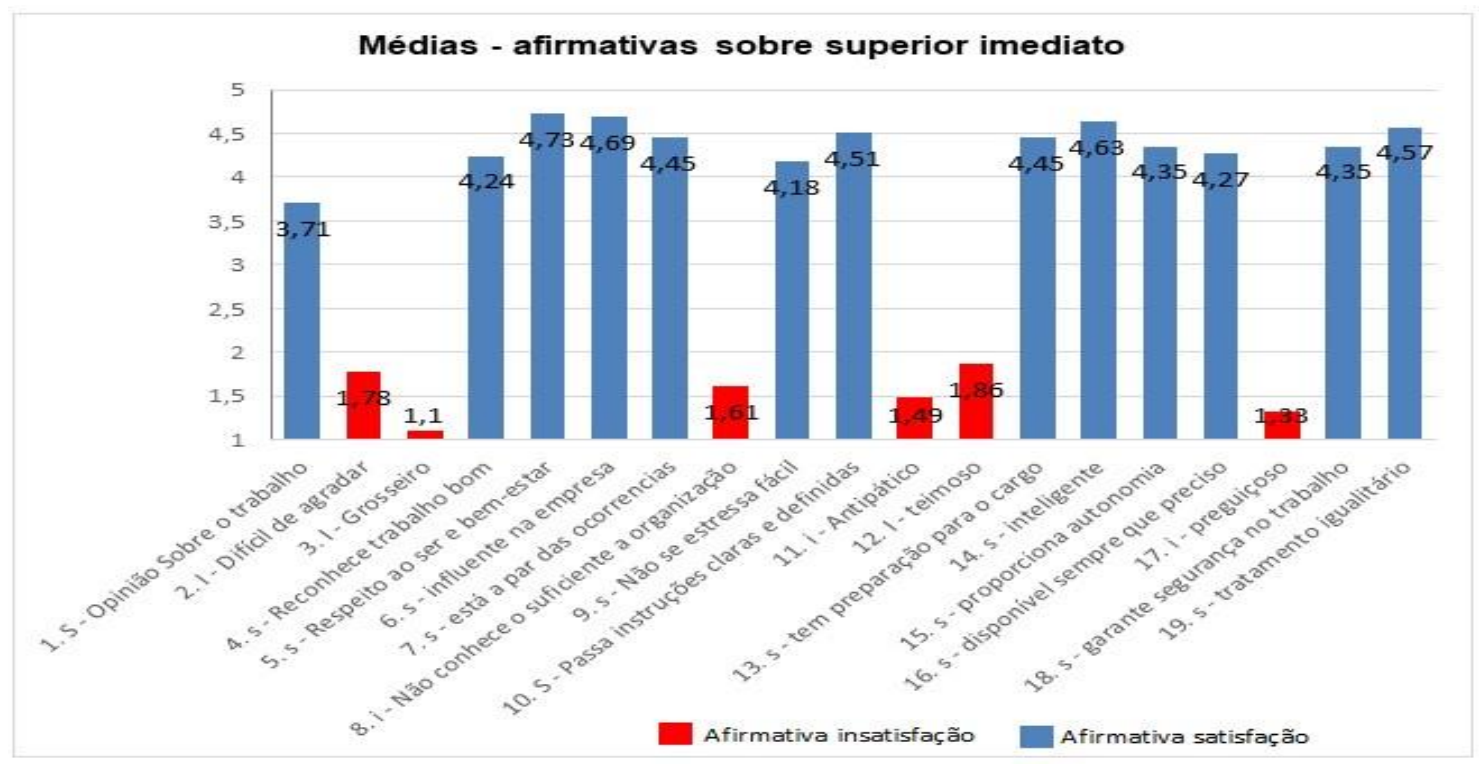

Gráfico 2 - Médias de Satisfação com a dimensão superior imediato.

Fonte: Própria 


\section{c) Satisfação com a equipe de trabalho}

Conforme o Gráfico 3, na dimensão de satisfação dos funcionários com a equipe de trabalho, afere-se que também estão satisfeitos. A média das 12 afirmativas que demonstrariam insatisfação apresentou ser de 2,16, o que representa que discordam em partes que ocorram tais situações na relação aos colegas. As 5 afirmativas que sugerem satisfação tiveram pontuação acima de 4, tendo como média geral 4,27.

Salienta-se entre as afirmativas com teor de insatisfação a opção 14.i - intrometem-se na minha vida, obtendo a menor média, 1,45. Este dado também pode ser associado ao fator respeito mencionado nas dimensões anteriores se observarmos que esta afirmativa reflete que a condição humana individual não é pauta para abordagens na organização. Porém, pode-se também supor que hajam outros fatores que levem a tal resultado.

A maior média dentre as afirmativas de insatisfação ficou no nível 3 e aponta que os colaboradores nem concordam e nem discordam de que seus companheiros se estressam facilmente, 9.i. O estresse é um fator que se expressa de diversas formas e pode se originar por diversas situações e ambientes. Havendo certa frequência em episódios, principalmente no trabalho, o ser pode ser afetado seriamente. De acordo com a Organização Pan-Americana de Saúde / Organização Mundial da Saúde - OPAN/OMS (2016):

\footnotetext{
Embora o impacto do estresse no local de trabalho varie de um indivíduo para o outro, ele é conhecido por trazer consequências para a saúde que variam de transtornos mentais a doenças cardiovasculares, músculo esqueléticas e reprodutivas. O estresse no trabalho também pode levar a problemas comportamentais, incluindo abuso de álcool e drogas, aumento do tabagismo e distúrbios do sono.
}

Duas afirmativas com médias acima de 2,5 chamam atenção: "membros da equipe insatisfeitos", 2.i, e que "conversam muito durante o trabalho", 10.i. Mesmo que ambas estejam no nível de discordar em partes, indica que a prática de conversar muito durante o expediente existe. Neste caso deve-se recordar que isso pode expressar indicativo do início de ataque contra a empresa, como mencionado por Ribeiro (1993, p.38) ao listar possíveis ações de um funcionário insatisfeito. 


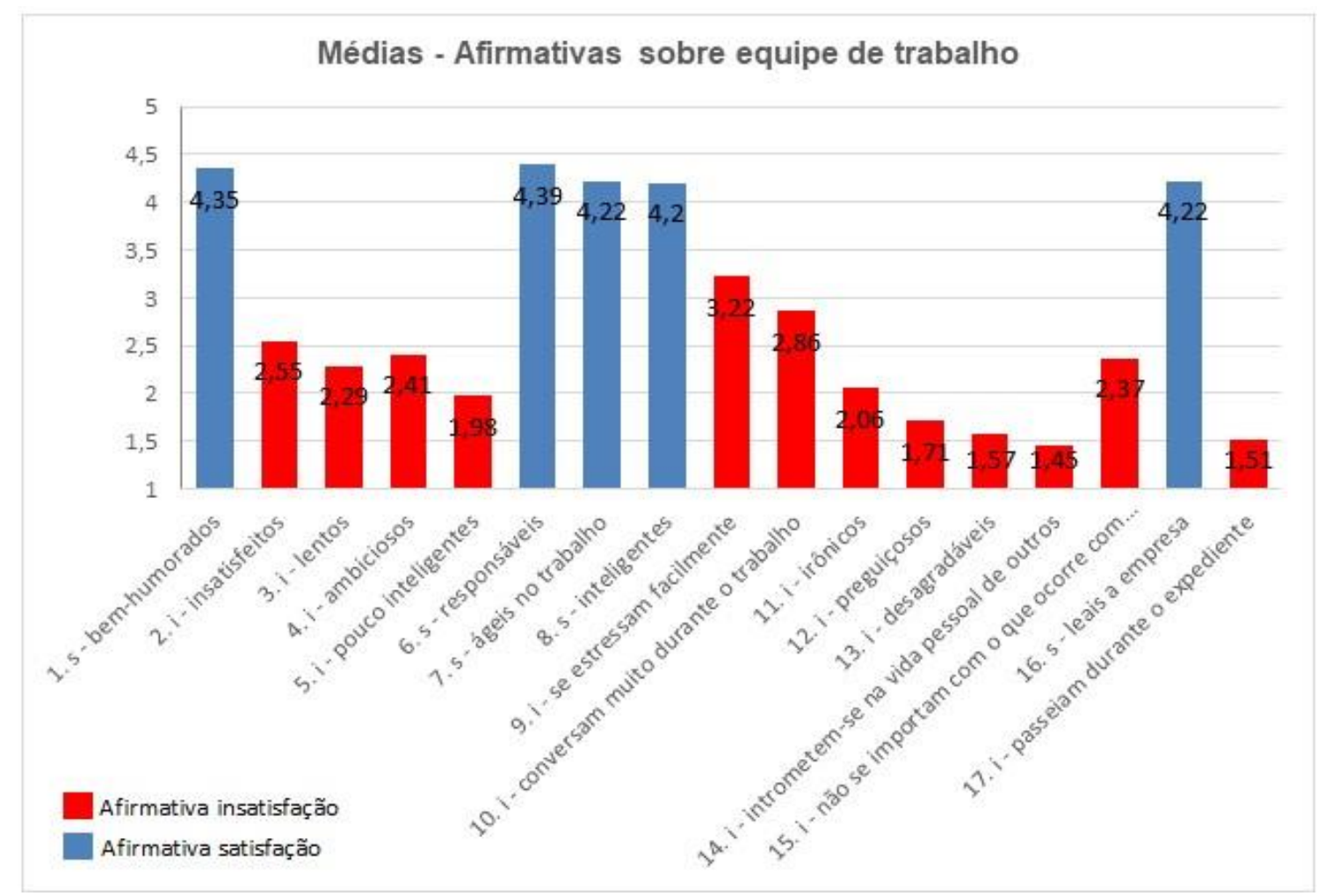

Gráfico 3 - Médias de Satisfação com a dimensão equipe de trabalho Fonte: Própria

d) Satisfação com a possibilidade de ascensões de cargo

Na presente e na última dimensão de satisfação no trabalho, a quantidade de afirmativas para análise é menor que nas dimensões anteriores, bem como é reduzida a escala Likert de 5 para 3 alternativas. Isso se dá por conta destas dimensões representarem variáveis extrínsecas ao colaborador que requerem respostas objetivas do tipo sim, não sei e não.

Como mostra o Gráfico 4 existem apenas duas afirmativas indicando satisfação, quais obtiveram média total de 2,48 segundo os respondentes. Quanto as 3 afirmativas de teor insatisfatório apreende-se que receberam média 1,75 , bem próximo da casa 2 indicando que há discordância em partes com estas.

Com média 2,43, a maioria dos colaboradores afirmam que na organização existem oportunidades de promoção. Interessante citar que dentre as alternativas se sobressaiu a afirmativa de satisfação onde os colaboradores creem que as ascensões são baseadas na observação das capacidades dos funcionários, tendo esta apresentado a maior média da dimensão, sendo pouco superior a 2,5. 
Corroborando com as considerações justas da pesquisa, com média 1,53 na assertiva 4.i, de teor insatisfatório, os respondentes defendem que as políticas de ascensão da empresa não são injustas. Apresentando pontuação de 1,67, os entrevistados informaram que não há frequência de ascensões de cargo, o que pode ser encarado como positivo considerando-se que esse tipo de frequências pode supor turnover, alocações de pessoal para cargos inadequados ao perfil e competências, baixa satisfação de funcionários de níveis altos com os cargos que ocupam, etc. Nota-se que em geral as médias desta dimensão tendem ao nível 2, o que pode indicar a possibilidade de sugerir que a organização busque rever seu plano promocional, tendo em vista que este é um fator motivador forte da satisfação no trabalho, que causa maior engajamento dos servidores a fim de conquistar a ascensão.

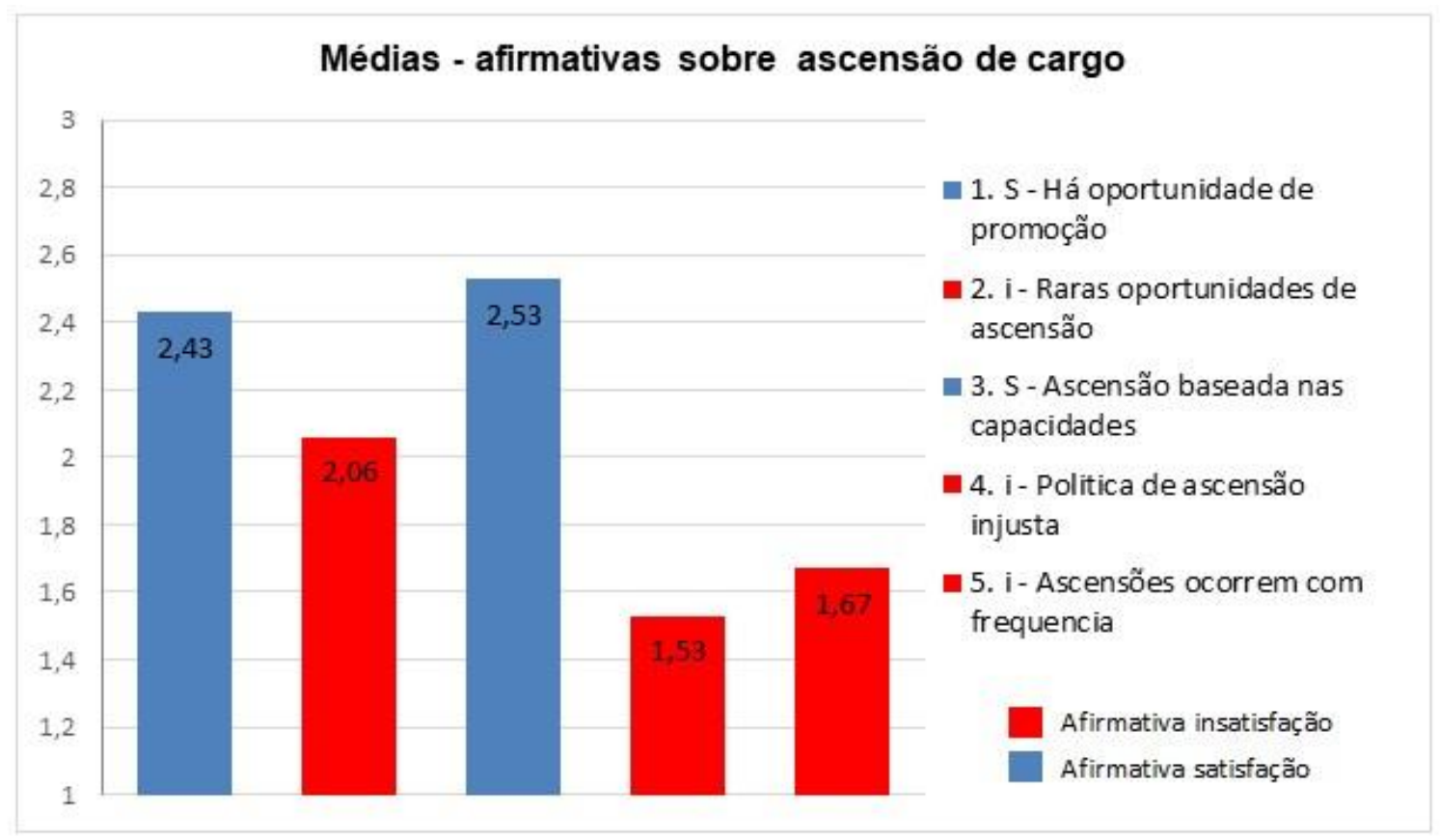

Gráfico 4 - Médias de Satisfação com a dimensão ascensão de cargo Fonte: Própria

\section{e) Satisfação com a remuneração}

De acordo com o Gráfico 5, com as frequências de satisfação obteve-se média 2,07. Este dado aponta que os funcionários não concordam nem discordam em estarem satisfeitos com o salário que recebem. Coerente com a média mencionada, as afirmativas de insatisfação pontuaram em 1,77, discordando em partes com o que lhes foi indagado. 
Em um contexto abrangendo as dimensões de satisfação com pontuações pouco acima de 2, os respondentes não concordam nem discordaram quanto as afirmativas: $1 . \mathrm{s}$ - salário suficiente para despesas básicas como alimentação e contas da casa, 3.s proporciona uma vida confortável, 6.s - salário bom e 8.s - salário justo para o cargo.

Destaque para o item 2.s que questionou se os respondentes consideram que a empresa distribui seus lucros de forma justa, qual foi a única afirmativa de satisfação a ficar a baixo do nível 2, indicando discordância parcial com média 1,69, mas isto não aponta que considerem seu salário ruim, como representa a média na afirmativa de insatisfação, 1,61.

As respostas apresentaram que a remuneração de algum modo varia, isso se explica quando em determinados meses alguns funcionários precisam trabalhar em feriados ou domingos, havendo nestes casos um acréscimo no valor da diária, esclarecendo deste modo que nenhum recebe valor inferior a 1 salário mínimo como rege a lei. Com a mesma média 1,86, pode-se afirmar que alguns respondentes tendem a não concordar nem discordar quanto a receber salário inferior à sua qualificação profissional.

Esta dimensão apresentou-se como a de menor nível de satisfação para os colaboradores, porém não demonstrando motivos ou indícios que indiquem motivos de aversão pelos funcionários.

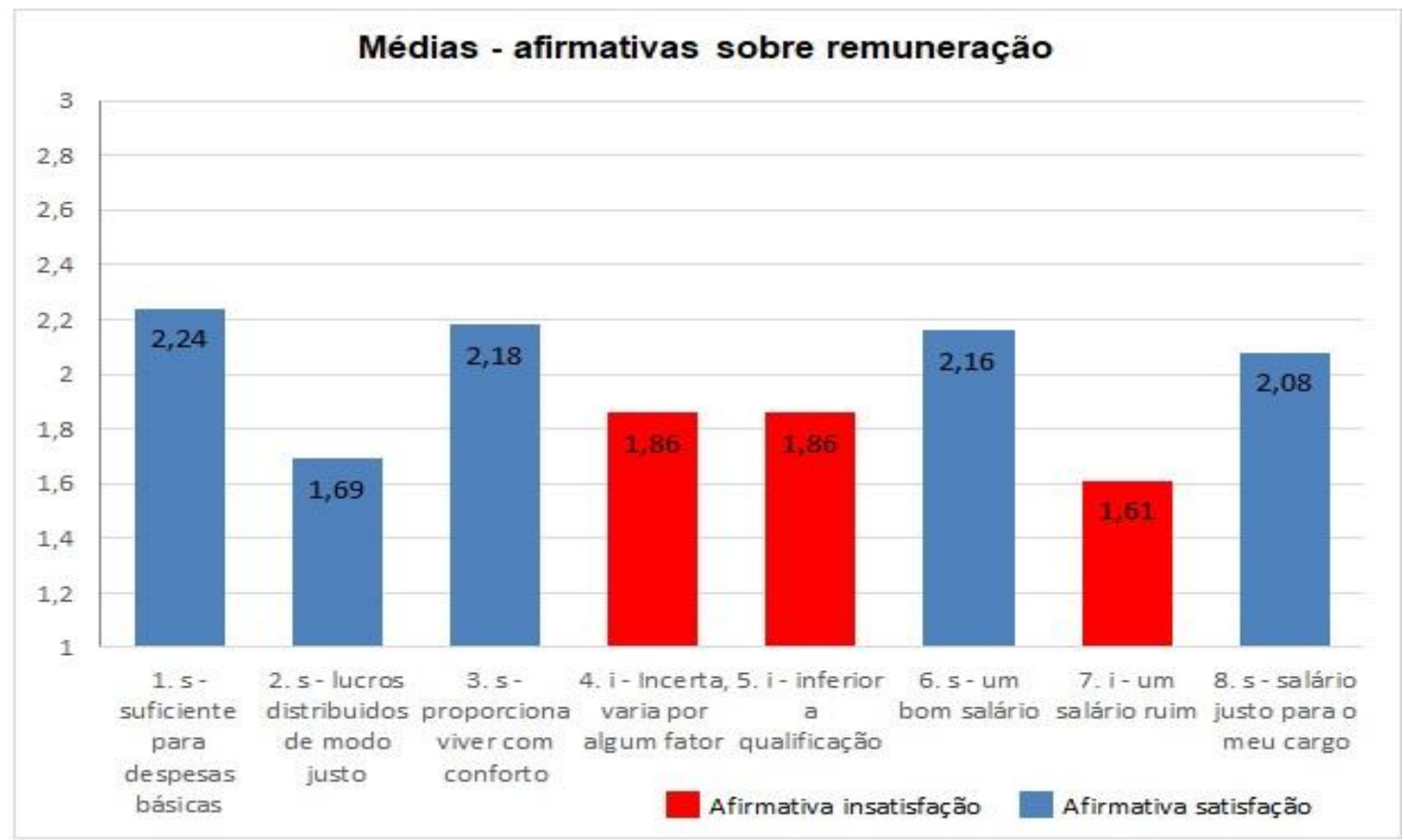

Gráfico 5 - Médias de Satisfação com a dimensão remuneração.

Fonte: Própria 


\subsection{Nível de Qualidade de Vida no Trabalho}

Após análise dos resultados das dimensões de satisfação, examinaremos as informações que compõem o Gráfico 6, onde constam 6 das 8 dimensões propostas pelo modelo de Walton para avaliar o nível de Qualidade de Vida no Trabalho comparando com os resultados das dimensões de satisfação estudados. A proposta de inserir esta parte teve como objetivo fazer um comparativo final que possa validar as perceções individuais com as coletivas sobre o ambiente.

O termo constitucionalismo está ligado a existência de regras, normas de convívio no ambiente. Este foi o indicativo que mais se destacou na pesquisa, obtendo média 4,53. Em termos de coerência com os dados analisados nas dimensões de satisfação pode-se comprovar que nas 3 dimensões de fatores intrínsecos esta característica foi a que mais se destacou. Na dimensão trabalho as maiores médias foram 4,71 em 7.S - Trabalho respeitado, e respetivamente 4,69, 16.S - Respeito a condição humana e identidade. Na dimensão sobre o superior imediato o mesmo ocorreu, apresentando média 4,73, na afirmativa 5.s Respeito ao ser e interesse pelo bem-estar, e por fim, na dimensão equipe de trabalho a afirmativa de ordem insatisfatória apresentou a média mais baixa, 1,45 para a afirmativa "14.I - Intrometem-se na minha vida", o que apresentou que há muito respeito a individualidade do ser na organização.

Quanto ao segundo indicador com melhor avaliação dos respondentes, as condições de trabalho adequadas podem ser avaliadas se comparada à média 4,29, com a média geral dos resultados considerando as 12 afirmativas de satisfação com o trabalho que corresponderam a 4,22 e as afirmativas de teor oposto com média 2,66, quais discordam em parte com o que foi questionado.

Integração social no trabalho foi o terceiro indicador mais bem avaliado, média 4,16. Em um contexto que abranja as perspetivas intrínsecas, identificaremos afirmativas com médias altas que se relacionem e comprovem esta afirmação, a exemplo na dimensão trabalho em equipe temos 1.s - Bem-humorados com média 4,35, na dimensão de afirmativas sobre o superior imediato observamos a disponibilidade em 19.s com média 4,57 indicando bom relacionamento deste com os colaboradores e, em detalhes relatados de modo oral durante a pesquisa, foi comentado que existem momentos de reunião onde podem compartilhar ideias, apresentar demandas e conhecer melhor as pessoas que compõem as lojas. 
Oportunidades de uso e desenvolvimento de capacidades e de crescimento e segurança ficaram com médias semelhantes, na casa de 3,8. Essa média indica que a maioria dos respondentes nem concordam nem discordam com estas afirmativas, porém tendem mais ao nível 4 que indica concordar com estas possibilidades. De fato pode-se citar a exemplo a afirmativa permite-me ser criativo com média 4,02 e sobre autonomia por parte do superior imediato cuja média foi 4,35, que desta forma pode estar proporcionando desenvolvimento de capacidade que consequentemente podem levar a ascensão futura do colaborador. Além de principalmente a média da dimensão ascensão de cargo estar também nas mesmas condições com média geral de satisfação em 2,48, e nas afirmativas de insatisfação 1,75 .

O último parâmetro, por ordem decrescente, é a compensação justa e adequada. Assim como na avaliação da dimensão da satisfação este indicador ficou com média no campo central que retrata que não há como concordar ou discordar mediante falta de informações ou quiçá receio em se demonstrar insatisfação.

Deste modo percebe-se que há conexão entre o nível de satisfação e qualidade de vida no trabalho do empreendimento Pão Mix.

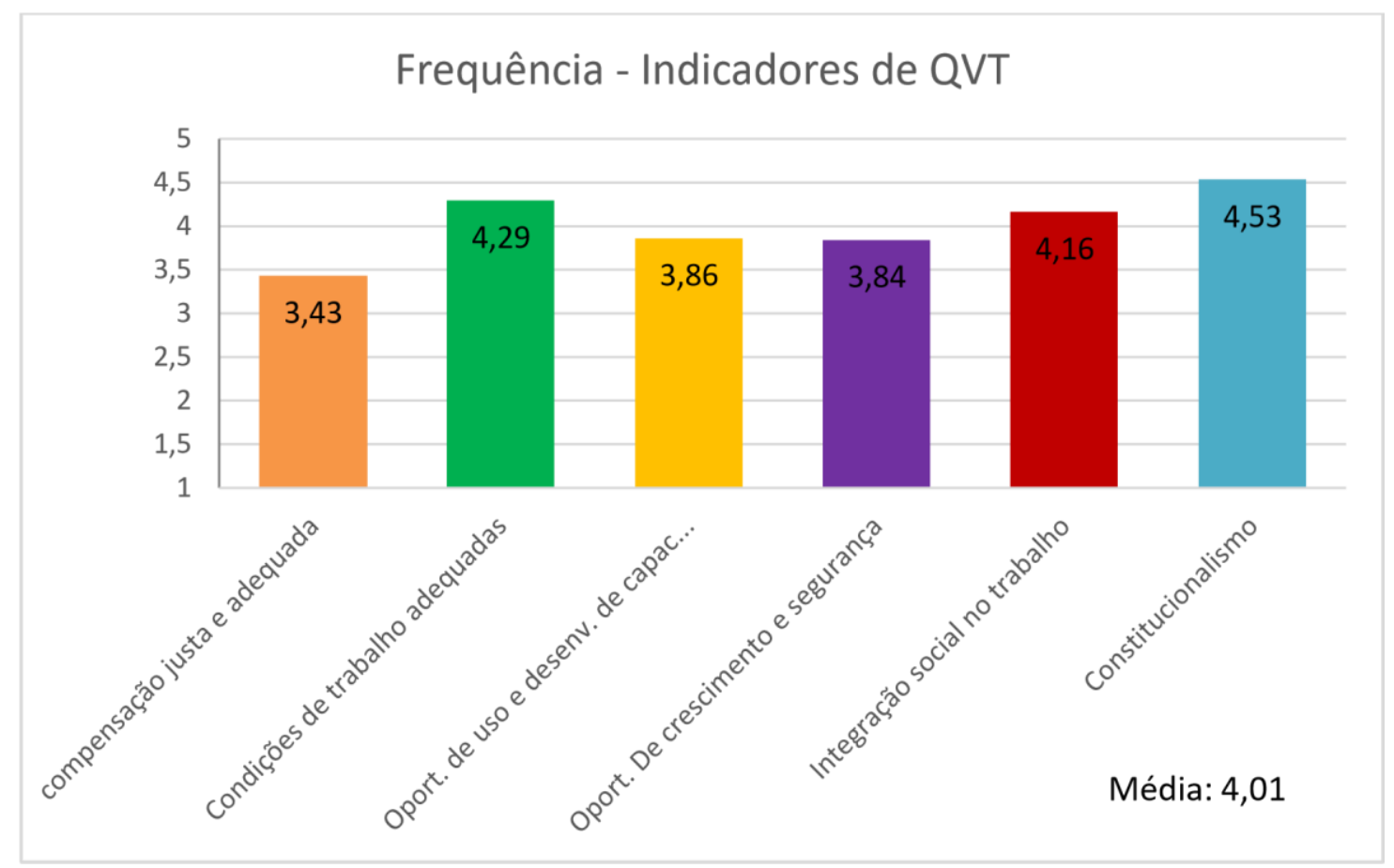

Gráfico 6 - Médias dos indicadores de Qualidade de Vida no Trabalho Fonte: Própria. 


\section{CONSIDERAÇÕES FINAIS}

Parte significativa da vida e do desenvolvimento humano se constrói dentro do ambiente de trabalho, espaço que exerce influencia direta na condição humana. Contudo, para que o homem encontre significado e desenvolva afeição pelo que realiza, precisa encontrar motivos que o faça sentir satisfação diante dos fatores que possam ocorrer, quais compõem a empresa e sua vida particular.

Essa satisfação, que está sujeita a influências de ações internas e externas ao ambiente de trabalho, é necessária tanto para proporcionar qualidade de vida ao colaborador, quanto para o progresso da organização. Em casos adversos, a insatisfação poderá gerar consequências negativas para ambos, afetando, por exemplo, a saúde física e mental do trabalhador, interferindo em seu comportamento psicossocial e na produtividade e desempenho de suas responsabilidades para a empresa.

Assim fundamentada, a pesquisa apresenta informações com relação à satisfação no trabalho baseada em dados coletados com colaboradores das lojas Pão Mix em Sobral - CE, constando detalhes sobre o perfil sociodemográfico, dimensões de satisfação e perceção sobre indicadores de Qualidade de vida no trabalho. Para tanto, foi efetuada pesquisa com foco nas cinco dimensões da satisfação no trabalho: natureza do trabalho, superior imediato, equipe de trabalho, possibilidade de ascensão de cargo e remuneração.

Os respondentes se mostraram satisfeitos com as condições que caracterizam o seu trabalho, o que pode significar que estejam designados nas áreas e setores baseados em suas habilidades e conhecimentos, além de estarem em um ambiente adequado ao seu bem-estar. Também se mostraram satisfeitos com seu superior imediato e equipe de trabalho. Esta satisfação pode ser vinculada ao relacionamento interpessoal, já que a ênfase maior se deu nas afirmativas que indicam respeito. Pode-se inferir que a instituição possui um bom ecossistema de trabalho. Foi possível identificar certa indiferença em relação às afirmativas de ascensão na organização. Essa consideração pode ser resultado da grande quantidade de funcionários com menos de um ano na organização, o que sugere pouco conhecimento sobre esta dimensão.

Encerrando a análise das dimensões, a escala de remuneração recebeu a menor média, porém figurando na alternativa que equivale a "não concordo e nem discordo". Neste caso, sugere-se que, diante de suas condições, a empresa reveja seu plano de remunerações, observando detalhes como esforço físico, periculosidade, 
responsabilidade auferida aos cargos de trabalho, entre outros que e realize ajustes, se necessários. Outra sugestão neste quesito visando compensar ou satisfazer os funcionários pode ser por meio de convênios com empresas locais ou regionais que proporcionem opções de lazer, saúde e/ou bem-estar, ou a própria empresa disponibilizar alguns benefícios de modo mensal, bimestral ou com na frequência que puder.

Comparando todas as médias e algumas afirmativas dispostas nas dimensões estudas com os índices de Qualidade de vida, quais obtiveram média 4,01, concluiu-se que há certa coerência no cruzamento de dados, indicando satisfação com a maior parte das condições. Para se chegar a essa conclusão, as Escalas de Satisfação com o emprego, elaborada por Sarathy e Barbosa e os indicadores de QVT do modelo de Walton foram de grande importância, sendo por intermédio destas que se conheceram detalhes das cinco dimensões da satisfação no trabalho e relacioná-las com a qualidade de vida presente naquela organização.

Para trabalhos futuros referentes ao tema, sugere-se incluir no questionário sociodemográfico uma opção que investigue o grau de escolaridade, por essa ter ligação com a satisfação ou insatisfação com as dimensões trabalho e, principalmente, remuneração. A tabulação dos dados realizada no software SPSS 22.0, está à disposição da empresa, tendo em vista que as informações podem dar margem para várias outras simulações que possam ser úteis para conhecer mais detalhes sobre o perfil de satisfação dos colaboradores. A partir das análises, encerra-se concluindo que, a satisfação no trabalho poderá ser melhorada pela organização doravante o entendimento das necessidades dos colaboradores e consequente criação de oportunidades baseadas nas áreas que necessitem de atenção.

De modo geral, a organização é digna de reconhecimento pelo considerável índice de satisfação apresentado na maior parte das variáveis estudadas. Mas, se sugere que a busca pelo conhecimento do nível de satisfação dos funcionários passe a ser realizada com mais frequência, mesmo que através de outros métodos. Isso representa cuidado e valorização com as pessoas que acreditam e ajudam a erguem o nome do empreendimento diariamente. 


\section{REFERÊNCIAS BIBLIOGRÁFICAS}

Alves, E. F. (2010). Qualidade de vida no trabalho: indicadores e instrumentos de medidas. Diálogos \& Saberes, 6(1), 77-87.

Azevedo, A. J. D., \& Medeiros, M. P. M. (2012). Satisfação no trabalho: um estudo de caso na Procuradoria-Geral de Justiça do Rio Grande do Norte. Revista Eletrônica Machado Sobrinho, 1(1), 1-18.

Bergamini, C. W, \& Tassinari, R. (2008). Psicopatologia do comportamento organizacional: Organizações Desorganizadas, mas Produtivas. São Paulo: Cengage Learning.

Bergamini, C. W. (1980). Desenvolvimento de recursos humanos: uma estratégia de desenvolvimento organizacional. São Paulo: Atlas.

Bergamini, C. W. (2010). Psicologia aplicada à administração de empresas: psicologia do comportamento organizacional. São Paulo: Atlas.

Bonfim, T. M., Stefano, S. R., \& Andrade, S. M. (2010). Satisfação e motivação no trabalho dos servidores públicos de uma prefeitura de pequeno porte do estado do Paraná: uma análise a partir do clima organizacional. SemeAD, XIII., Seminários em administração 2010, 9 e 10 de setembro de 2010, São Paulo, Brasil.

Carvalho, T. M. X. B. (2002). O homem nas organizações. Revista Centro de Ciências Administrativas, 8(1), 32-37.

Chiavenato, I. (2002). Recursos Humanos. São Paulo: Atlas.

Chiavenato, I. (2003). Introdução à teoria geral da administração: uma visão abrangente da moderna administração das organizações. Rio de Janeiro: Elsevier.

Chiavenato, I. (2004). Gestão de pessoas: e o novo papel dos recursos humanos nas organizações. (2. ${ }^{\text {a }}$ ed.). Rio de Janeiro: Elsevier.

Dejours, C., \& Abdoucheli, E. (1994). Itinerário teórico em psicopatologia do trabalho. Psicodinâmica do trabalho: contribuições da escola dejouriana à análise da relação prazer, sofrimento e trabalho. São Paulo: Atlas.

Frankl, V. (2003). Sede de sentido. São Paulo: Quadrante. 
Karpinski, D., \& Stefano, S. R. (2008). Qualidade de vida no trabalho e satisfação um estudo de caso no setor atacadista de beneficiamento de cereais. Revista Eletrônica Lato Senso, 3(1). Disponível em: http://www.unicentro.br

Klijn, T. M. P. (1998). Satisfação no trabalho de mulheres acadêmicas da Universidade de Concepción. (Tese de Doutorado). Escola de Enfermagem de Ribeirão Preto e Escola de Enfermagem, Universidade de São Paulo, São Paulo.

Marqueze, E. C., \& Castro Moreno, C. R. (2005). Satisfação no trabalho - uma breve revisão. Revista Brasileira de Saúde Ocupacional, 30(112), pp. 69-79

Martinez, M. C, \& Paraguay, A. I. B. B. (2003). Satisfação e saúde no trabalho: aspectos conceituais e metodológicos. Cadernos de psicologia social do trabalho, 6, 59-78.

Martinez, M. C., Paraguay, A. I. B. B., \& Latorre, M. R. D. O. (2004). Relação entre satisfação com aspectos psicossociais e saúde dos trabalhadores. Revista de Saúde Pública, 38(1), 55-61. doi:10.1590/S0034-89102004000100008

Mendes, H. B. (2014). Fatores motivacionais e sua influência no comportamento humano. (Trabalho de Conclusão de Curso do Curso de Administração). Santa Catarina - UNESC. Brasil.

Moretti, G. J. S. (2010). O perfil e a satisfação no trabalho dos professores dos cursos de graduação em administração das instituições de Cursos superiores Privadas da cidade de Ribeirão Preto (SP). (Dissertação de Mestrado). Universidade de São Paulo, São Paulo Brasil.

Motta, P. R. (2001). Transformação Organizacional: a teoria e a prática de inovar. Rio de Janeiro: Qualitymark.

Oliveira, M. A. (2010). Comportamento Organizacional para Gestão de Pessoas: como agem as empresas e seus gestores. São Paulo: Saraiva.

OPAN/OMS. Estresse no ambiente de trabalho cobra preço alto de indivíduos, empregadores e sociedade. Disponível em <http://www.paho.org

Passarinho, M. L. G., Passarinho, G. da S., Silva, J. W. M., Cardoso Junior, J. T., \& Ribeiro Neto, A. S. (2016). Qualidade de vida no trabalho dos bombeiros militares e policiais, 2016. Disponível em:

http://www.eumed.net/rev/caribe/2016/06/bombeiros.html

Pereira, J. P. E. (2006). A satisfação no trabalho: uma aplicação ao sector hoteleiro da Ilha de São Miguel. (Dissertação de Mestrado). Universidade dos Açores, Portugal. 
Pereira, M. A. M. (2003). Entendendo fatores que interferem na satisfação no trabalho. (Monografia - Graduação em Psicologia). Universidade Federal de São Carlos, São Carlos, Brasil.

Rebouças, D., Legay, L. F., \& Abelha, L. (2007). Satisfação com o trabalho e impacto causado nos profissionais de serviço de saúde mental. Revista de Saúde Pública, 41(2), 244-250, 2007.

Ribeiro, C. R. M. (1993). A Empresa Holística. Petrópolis, RJ: Vozes.

Ribeiro, L. A., \& Santana, L. C. (2015). Qualidade de vida no trabalho: fator decisivo para o sucesso organizacional. RIC Cairu, 2(2), 75-96, 2015.

Sarathy, R., \& Barbosa, J. D. (1981). Fatores explicativos da permanência e saída do emprego. Revista de Administração de Empresas, 21(1), 17-29.

Spector, P. E. (2003). Psicologia nas organizações. São Paulo: Saraiva.

Tamayo, A. (1998). Valores organizacionais: sua relação com satisfação no trabalho, cidadania organizacional e comprometimento afetivo. Revista de Administração, 33(3), 56-63.

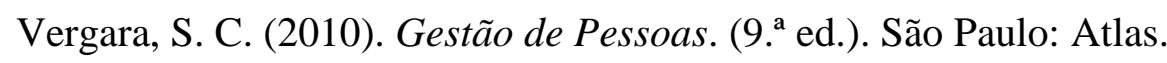

Yin, R. K. (2001). Estudo de caso: planejamento e métodos. (2. ${ }^{\mathrm{a}}$ ed.). Porto Alegre: Bookman. 


\section{QUESTIONÁRIO}

\section{ANEXO I- Questionário aplicado}

Este questionário é composto de três partes: (1) dados sociodemográficos, (2) afirmativas sobre sua satisfação no trabalho levando em conta 5 variáveis nas três primeiras dimensões e com 3 variáveis nas duas últimas, e (3) avaliação sobre as variáveis de qualidade de vida no trabalho. Suas respostas serão mantidas em total sigilo. Serão tratadas apenas pelos responsáveis da pesquisa e os resultados serão apresentados em termos gerais. Agradeço sua colaboração dedicando alguns minutos do seu tempo ao respondê-lo, visto que os resultados poderão contribuir com melhores conhecimentos sobre o tema. 0 resultado da pesquisa estará a disposição, é só contatar pelo e-mail: samulima4@gmail.com.

\section{(1) Pesquisa sociodemográfica}

Nas questões a seguir, assinale o item correspondente ao seu perfil:

\begin{tabular}{|c|c|c|c|c|c|c|c|}
\hline \multicolumn{8}{|l|}{ Sexo } \\
\hline & \multicolumn{3}{|l|}{ Masculino } & \multicolumn{4}{|c|}{ Feminino } \\
\hline \multicolumn{8}{|c|}{ Faixa etária } \\
\hline & \multicolumn{2}{|l|}{ Até 20 anos } & \multicolumn{3}{|c|}{ De 30 a 34} & \multicolumn{2}{|l|}{ De 40 a 59} \\
\hline & \multicolumn{2}{|l|}{ De 21 a 29} & \multicolumn{3}{|c|}{ De 35 a 39} & \multicolumn{2}{|c|}{ Acima de 60 anos } \\
\hline \multicolumn{8}{|c|}{ Estado civil } \\
\hline & Solteiro & \multicolumn{2}{|l|}{ Casado } & \multicolumn{3}{|l|}{ Divorciado } & Viúvo \\
\hline & \multicolumn{7}{|l|}{ Outro: } \\
\hline \multicolumn{8}{|c|}{ Faixa salarial mensal (salário mínimo, s.m., em reais). } \\
\hline & De 1 a 2 s.m. & \multicolumn{3}{|c|}{ Mais de 5 a 10 s.m. } & \multicolumn{3}{|l|}{ Acima de 20 s.m. } \\
\hline & Mais de 2 a 5 s.m. & \multicolumn{6}{|c|}{ Mais de 10 s.m. a 20 s.m. } \\
\hline \multicolumn{8}{|c|}{ Posição ocupada na instituição } \\
\hline & \multicolumn{7}{|c|}{ Nível estratégico: Presidente, vice-presidente, superintendente, diretor, assessor; } \\
\hline & \multicolumn{7}{|c|}{ Nível tático especializado: gerente, coordenador, supervisor, analista/técnico especial, assistente administrativo; } \\
\hline & \multicolumn{7}{|c|}{ Nível operacional: agente administrativo, técnico, operador, atendente. } \\
\hline \multicolumn{8}{|c|}{ Tempo de trabalho na instituição } \\
\hline & \multicolumn{3}{|l|}{ Até 11 meses } & \multicolumn{4}{|c|}{ De 5 anos a 9 anos e 11 meses } \\
\hline & \multicolumn{3}{|c|}{ De 1 ano a 1 ano e 11 meses } & \multicolumn{4}{|c|}{ De 10 anos a 14 anos e 11 meses } \\
\hline & \multicolumn{3}{|c|}{ De 2 anos a 4 anos e 11 meses } & \multicolumn{4}{|c|}{ Acima de 15 anos } \\
\hline
\end{tabular}

(2) Questionário sobre fatores de satisfação no trabalho

A seguir, são apresentadas afirmativas que tratam de aspetos relacionados à sua satisfação com o trabalho e comprometimento organizacional. Considerando-se que não há respostas "certas" ou "erradas", favor não deixar de responder a questão alguma. Utilize a escala progressiva a seguir, que varia de 1 a 5 nas afirmativas sobre

TRABALHO, SUPERIOR IMEDIATO e EQUIPE DE TRABALHO, e a escala progressiva de 1 a 3 nas afirmativas ASCENSÃO DE CARGO e REMUNERAÇÃO, para expressar sua opinião, marcando a opção que mais se adeque ao seu perfil.

DISCORDO TOTALMENTE (DT)

DISCORDO EM PARTES (DP)

NÃO CONCORDO NEM DISCORDO (NC/ND)

CONCORDO EM PARTES (CP)

CONCORDO TOTALMENTE (CT) 


\begin{tabular}{|c|l|c|c|c|c|c|}
\hline № & AFIRMATIVAS SOBRE O TRABALHO & DT 1 & DP 2 & NC/ND 3 & CP 4 & CT 5 \\
\hline 1 & Encantador & 1 & 2 & 3 & 4 & 5 \\
\hline 2 & Monótono & 1 & 2 & 3 & 4 & 5 \\
\hline 3 & Satisfatório & 1 & 2 & 3 & 4 & 5 \\
\hline 4 & Enfadonho / chato & 1 & 2 & 3 & 4 & 5 \\
\hline 5 & Bom & 1 & 2 & 3 & 4 & 5 \\
\hline 6 & Me permite ser criativo & 1 & 2 & 3 & 4 & 5 \\
\hline 7 & Respeitado & 1 & 2 & 3 & 4 & 5 \\
\hline 8 & É climatizado & 1 & 2 & 3 & 4 & 5 \\
\hline 9 & Prazeroso & 1 & 2 & 3 & 4 & 5 \\
\hline 10 & Saudável & 1 & 2 & 3 & 4 & 5 \\
\hline 11 & Desafiador & 1 & 2 & 3 & 4 & 5 \\
\hline 12 & Exaustivo & 1 & 2 & 3 & 4 & 5 \\
\hline 13 & Frustrante & 1 & 2 & 3 & 4 & 5 \\
\hline 14 & Prolongado/extenso & 1 & 2 & 3 & 4 & 5 \\
\hline 15 & Me proporciona realização pessoal & 1 & 2 & 3 & 4 & 5 \\
\hline 16 & Respeita minha condição humana e identidade & 1 & 2 & 3 & 4 & 5 \\
\hline 17 & Me realiza profissionalmente & 1 & 2 & 3 & 4 & 5 \\
\hline
\end{tabular}

\begin{tabular}{|c|l|c|c|c|c|c|}
\hline$N^{\circ}$ & \multicolumn{1}{|c|}{ AFIRMATIVAS SOBRE O SUPERIOR IMEDIATO } & DT 1 & DP 2 & NC/ND 3 & CP 4 & CT 5 \\
\hline 1 & Pede minha opinião quanto a assuntos ligados ao meu trabalho & 1 & 2 & 3 & 4 & 5 \\
\hline 2 & Difícil de agradar & 1 & 2 & 3 & 4 & 5 \\
\hline 3 & Grosseiro & 1 & 2 & 3 & 4 & 5 \\
\hline 4 & Sabe reconhecer um trabalho quando bem feito & 1 & 2 & 3 & 4 & 5 \\
\hline 5 & Trata-me como ser humano e se interessa pelo meu bemestar & 1 & 2 & 3 & 4 & 5 \\
\hline 6 & É influente na empresa & 1 & 2 & 3 & 4 & 5 \\
\hline 7 & Está a par do que ocorre na organização & 1 & 2 & 3 & 4 & 5 \\
\hline 8 & Não busca conhecer o suficiente sobre o funcionamento da organização & 1 & 2 & 3 & 4 & 5 \\
\hline 9 & Não se estressa facilmente & 1 & 2 & 3 & 4 & 5 \\
\hline 10 & Passa instruções claras e definidas & 1 & 2 & 3 & 4 & 5 \\
\hline 11 & É antipático & 1 & 2 & 3 & 4 & 5 \\
\hline 12 & É teimoso & 1 & 2 & 3 & 4 & 5 \\
\hline 13 & Tem preparação e formação adequada para o cargo & 1 & 2 & 3 & 4 & 5 \\
\hline 14 & É inteligente & 1 & 2 & 3 & 4 & 5 \\
\hline 15 & Me proporciona autonomia & 1 & 2 & 3 & 4 & 5 \\
\hline 16 & Está disponível sempre que preciso & 1 & 2 & 3 & 4 & 5 \\
\hline 17 & Preguiçoso & 1 & 2 & 3 & 4 & 5 \\
\hline 18 & Cuida em garantir minha segurança no trabalho & 1 & 2 & 3 & 4 & 5 \\
\hline 19 & Trata os funcionários de modo igualitário, sem favoritismos & 1 & 2 & 3 & 4 & 5 \\
\hline
\end{tabular}

\begin{tabular}{|c|c|c|c|c|c|c|}
\hline № & AFIRMATIVAS SOBRE A EQUIPE DE TRABALHO & DT 1 & DP 2 & NC/ND 3 & CP 4 & CT 5 \\
\hline 1 & Bem-humorados & 1 & 2 & 3 & 4 & 5 \\
\hline 2 & Insatisfeitos & 1 & 2 & 3 & 4 & 5 \\
\hline 3 & Lentos & 1 & 2 & 3 & 4 & 5 \\
\hline 4 & Ambiciosos & 1 & 2 & 3 & 4 & 5 \\
\hline 5 & Pouco inteligentes & 1 & 2 & 3 & 4 & 5 \\
\hline 6 & Responsáveis & 1 & 2 & 3 & 4 & 5 \\
\hline 7 & Ágeis no trabalho & 1 & 2 & 3 & 4 & 5 \\
\hline 8 & Inteligentes & 1 & 2 & 3 & 4 & 5 \\
\hline 9 & Se chateiam/estressam facilmente & 1 & 2 & 3 & 4 & 5 \\
\hline 10 & Conversam muito durante o trabalho & 1 & 2 & 3 & 4 & 5 \\
\hline 11 & São irônicos & 1 & 2 & 3 & 4 & 5 \\
\hline 12 & São preguiçosos & 1 & 2 & 3 & 4 & 5 \\
\hline 13 & São desagradáveis & 1 & 2 & 3 & 4 & 5 \\
\hline 14 & Intrometem-se na minha vida & 1 & 2 & 3 & 4 & 5 \\
\hline 15 & Não se importam com o que acontece com a empresa & 1 & 2 & 3 & 4 & 5 \\
\hline 16 & Leais a empresa & 1 & 2 & 3 & 4 & 5 \\
\hline 17 & Costumam passear durante o expediente & 1 & 2 & 3 & 4 & 5 \\
\hline
\end{tabular}


DISCORDO TOTALMENTE (DT)

NÃO CONCORDO NEM DISCORDO (NC/ND)

CONCORDO TOTALMENTE (CT)

\begin{tabular}{|c|c|c|c|c|}
\hline № & AFIRMATIVAS SOBRE ASCENSÃO DE CARGO & DT 1 & NC/ND 2 & CT 3 \\
\hline 1 & Há oportunidades de ascensão de cargo & 1 & 2 & 3 \\
\hline 2 & Raras oportunidades de ascensão & 1 & 2 & 3 \\
\hline 3 & A ascensão é baseada nas capacidades do funcionário & 1 & 2 & 3 \\
\hline 4 & A política de ascensão na empresa é injusta & 1 & 2 & 3 \\
\hline 5 & As ascensões ocorrem com frequência & 1 & 2 & 3 \\
\hline
\end{tabular}

\begin{tabular}{|c|c|c|c|c|}
\hline № & AFIRMATIVAS SOBRE REMUNERAÇÃO & DT 1 & NC/ND 2 & CT 3 \\
\hline 1 & Suficiente para cobrir despesas básicas (Aluguel, água, luz, internet e alimentação) & 1 & 2 & 3 \\
\hline 2 & Os lucros da empresa são distribuídos de forma justa & 1 & 2 & 3 \\
\hline 3 & Me proporciona viver com conforto & 1 & 2 & 3 \\
\hline 4 & Incerta, varia por algum fator & 1 & 2 & 3 \\
\hline 5 & Inferior a minha qualificação & 1 & 2 & 3 \\
\hline 6 & Um bom salário & 1 & 2 & 3 \\
\hline 7 & Um salário ruim & 1 & 2 & 3 \\
\hline 8 & Salário justo para meu cargo & 1 & 2 & 3 \\
\hline
\end{tabular}

(3) Questionário de avaliação dos Indicadores de QVT

Assinale o nível de sua satisfação com cada indicador de Qualidade de Vida no Trabalho apresentados de acordo com suas condições de trabalho de modo que cada número corresponde: (1) Não Ocorre, (2) Não ocorre totalmente, (3) Não Sei se Ocorre ou Não; (4) Ocorre em Partes; (5) Ocorre Frequentemente.

\begin{tabular}{|c|l|c|c|c|c|c|}
\hline № & \multicolumn{1}{|c|}{ INDICADORES DETERMINANTES DE QVT } & NO1 & NOT 2 & NSON 3 & OP 4 & OF 5 \\
\hline 1 & Compensação justa e adequada & 1 & 2 & 3 & 4 & 5 \\
\hline 2 & Condições de trabalho adequadas & 1 & 2 & 3 & 4 & 5 \\
\hline 3 & Oportunidade de uso e desenvolvimento de capacidades & 1 & 2 & 3 & 4 & 5 \\
\hline 4 & Oportunidade de crescimento e segurança & 1 & 2 & 3 & 4 & 5 \\
\hline 5 & Integração Social no trabalho & 1 & 2 & 3 & 4 & 5 \\
\hline 6 & Constitucionalismo (Regras de convívio bem definidas) & 1 & 2 & 3 & 4 & 5 \\
\hline
\end{tabular}

